\title{
Elastic properties of thulium doped zinc borotellurite glass
}

\begin{abstract}
A series of Tm-doped zinc borotellurite glass have been extracted by conventional meltquenching method. The density was measured and it had been found that the value is increased by the increment of $\mathrm{Tm}^{3+}$ ion. The elastic properties of the sample were determined by measuring longitudinal and shear velocities using an ultrasound technique. Then the values inserted into equations that calculate the elastic moduli of the glass samples. These include longitudinal, shear, bulk, Young's modulus and also the Poisson's ratio. The longitudinal and shear velocities show an increment as $\mathrm{Tm}^{3+}$ increases from 0.01 to $0.03 \mathrm{~mol}$ content. The trend then changes as $\mathrm{Tm}^{3+}$ increases from 0.03 to $0.05 \mathrm{~mol}$ content. In terms of elastic moduli, it produces a rapid increment with $\mathrm{Tm}^{3+}$ until 0.03 mol content. But after that, the increment becomes slow until $0.05 \mathrm{~mol}$ of $\mathrm{Tm}^{3+}$. The value of Poisson's ratio decreases with the addition of $\mathrm{Tm}^{3+}$ concentration.
\end{abstract}

Keyword: Borotellurite; Bulk modulus; Elastic properties; Longitudinal modulus; Poisson's ratio; Young's modulus 